\title{
Nation Building and Economic Growth
}

\author{
By Ellyn Creasey, Ahmed S. Rahman, and Katherine A. Smith *
}

Nation building, the joint provision of economic and military aid in conflict or post-conflict areas, has been used as an important and expensive foreign policy tool. Yet despite the huge costs of these investments, the growth effects of nation building operations for recipient nations remain under-explored. While current literature documents the negative growth effects of conflict (Yamarik, Johnson and Compton (2010)) and the positive effects of economic aid after conflict (Collier and Hoeffler (2002)) very little has been done on the confluence of different kinds of aid and the effectiveness of such joint efforts during times of turmoil. This paper attempts to answer the following three questions regarding the growth effects of nation-building operations. Does the joint provision of economic and military assistance help a country grow when it is embroiled in conflict? Does such joint provision help a country grow in the direct aftermath of conflict? And finally, are there specific types and combinations of military and economic assistance that are more conducive to growth?

Estimating the degree of complementarity between economic and military aid empirically is particular revealing since, theoretically, their interaction is ambiguous. On the one hand military and economic aid in joint provision may bolster growth through a variety of complementary channels. One could boost spending while the other boosts security, both potentially in greater need during times of war. Yet such robust foreign intervention could destabilize growth by potentially creating a dependency to a foreign country or by fueling resentment or humiliation.

\footnotetext{
* Creasey: Ensign, U.S. Navy, creasey@gmail. Rahman: U.S. Naval Academy, Department of Economics, 589 McNair RD., Annapolis MD, 21402, USA, rahman@usna.edu.Smith: U.S. Naval Academy, Department of Economics, 589 McNair RD., Annapolis MD, 21402, USA, ksmith@usna.edu.
}

In this study we estimate the growth effects of nation building using a large crosscountry panel dataset. We measure nation building using a three-way interaction term of economic aid, military support and conflict regime. The estimation of these potential complementarities does require instrumentation because the under-developed and conflict-prone nature of these regions may itself motivate potential donors to provide more or less aid. We correct for this reverse causality by a two-stage estimation process. Specifically, we first estimate aid flows and then use the estimated values to measure the impact of nation building on growth.

To further explore the potential complementarities between economic and military aid during and directly after conflict, we next use disaggregated measures of aid to construct more nuanced measures of nation building endeavors. That is, we use measures of military assistance and economic aid that are delineated for particular purposes in order to measure the growth impact of specifically-motivated nation building activities. In so doing we attempt to open up the black box of foreign assistance to get some sense of what particular combinations of aid programs help countries grow during and after times of war.

\section{Empirical Approach and Data}

To address the question of potential complementarities between economic and military aid during or directly after war, we explore the interactions between different aid types and conflict scenarios in the context of a standard growth regression framework. As in Islam (1995), we log-linearize and first difference the steady-state equation from the Solow growth model (Solow (1956)) to construct a panel growth regression. In addition to including the fundamental variables of growth, we can in- 
clude other auxiliary explanatory factors (Durlauf and Quah (1998)). Our empirical strategy is to include various measures of economic and military assistance and measures of conflict and post-conflict periods along with the fundamental variables standard in neoclassical growth theory.

Specifically, the growth impacts of nation building are captured in the following framework:

$$
\begin{aligned}
\Delta y_{j, t}= & \mu_{j}+\kappa_{t}+\alpha * \ln y_{j, t}+ \\
& \sum_{i=1}^{3} \phi_{i} x_{j, t, i}+\sum_{i=1}^{11} \theta_{i} z_{j, t, i}+\epsilon_{j, t}
\end{aligned}
$$

$\mu_{j}$ and $\kappa_{t}$ represent country and time fixed effects. $y_{j, t}$ denotes GDP per capita for country $j$ at time $t$. The $x$ variables are those that proxy for standard variables in neoclassical growth theory (investment, education and population growth). The $z$ variables are those which we use to augment the canonical growth model. These include indicator variables for conflict and post-conflict periods, an indicator variable for the existence of external military assistance, a measure of external economic aid, and the various interactions between these variables. To assess the growth impacts of nation building, we must capture the effects of conflict and post-conflict periods when there is a confluence of military and economic assistance. Specifically, we interpret the marginal influence from nation building endeavors as the growth effect of an extra dollar of economic aid when the country receives military assistance either during a conflict or directly after a conflict. That is, we wish to distinguish between the gains from joint aid efforts when the receiver nation is at war versus the gains from such efforts when the nation is recovering from war.

We use a panel consisting of 176 countries over the years 1960 - 2005. All growth variables are calculated as threeyear growth rates. This is in order to isolate long-run growth effects as opposed to business cycle effects (Islam (1995)), as well as to better capture the longer-term effects of aid and conflict on growth (Collier and Hoeffler (2002)). GDP and investment data come from the Penn World Tables (2009). Education expenditure shares of GDP and population growth rates come from the World Bank Development Indicators (2009). The joint Uppsala Conflict Data Program and International Peace Research Institute (UCDP-PRIO) provides conflict-related data including the incidence and duration of conflicts, and the number of battle deaths.

We include a number of "aid" variables in the analysis. First, the International Military Intervention Dataset (2008) records all instances of military interventions over international boundaries by regular armed forces of independent states. Economic aid data come from two sources. The Organization for Economic Cooperation and Development and Development's Creditor Reporting System (OECD CRS 2007) document dollar aid flows from OECD member nations to receiver nations. The World Bank Projects Database (2008) on the other hand provides alternative measures of grants from donor to recipient nations.

To address the potential endogeneity of economic aid (aid may be given to regions more or less likely to succeed regardless of external aid funding), we also perform a two step procedure. Since aid may be provided in part for geopolitical considerations (as opposed to strictly economic considerations) one can use geopolitical factors as instruments for aid flows. Instrumenting aid flows using cultural or political variables was first developed by Alesina and Dollar (2000), who use colonial histories and political alliances to determine foreign aid.

In a similar spirit, we estimate bilateral aid flows using two types of geopolitical variables. The first measures the extent to which two countries are politically aligned, through an affinity index based on roll-call votes in the United Nations General Assembly from 1946-2008. We use this index as an explanatory variable in estimating aid flows. This is intended to capture the idea that aid donors may generally prefer to contribute resources to like-minded regimes, or that aid may be used to punish 
or reward regimes for voting in particular ways. The second type of variable measures the colonial relationships between country pairs, capturing the number of years the aid giver has or had been a colonizer of the aid receiver. Alesina and Dollar (2000) and others suggest that past colonial relations can be a strong motivator for current aid giving. We construct this colonial history using data from the CIA World Factbook.

\section{Results}

We first estimate the fixed effects growth regression model using our basic measures of economic and military aid. That is, our aid measure here is the total economic aid received by country $j$ for any developmental objective. Similarly, our military assistance measure here is an indicator variable which equals one when there is a friendly foreign military presence in country $j$, no matter what the stated military objective is. We do this for both instrumented and non-instrumented cases.

Results are reported in Table 1. Without including any aid variables, growth is stifled with conflict but appears to rebound directly after conflict. The inclusion of our measures of economic aid, military assistance and conflict regime yield some interesting results. First note that conflict clearly acts as a detriment to economic growth. Countries which experience conflict are associated with anywhere between $3 \%$ and $6 \%$ lower per capita growth. Of course it is impossible to tell here whether conflicts disrupt economic activities, or whether lower growth rates spur fighting.

Given that conflict tends to impede growth, we are interested in the effects of giving foreign aid to these nations embroiled in conflict. Including our economic aid variable and military aid indicator (econ and $\mathrm{mil}$ ) yields some interesting results. First, our economic aid figures that are provided during conflict, either instrumented or non-instrumented, appears to have some beneficial effects on growth. Military assistance during conflict is associated with lower growth. On the other hand, the presence of military assistance during those times just following a conflict is strongly associated with more rapid growth.

We are also interested in combinations of these interaction terms. Specifically, we wish to gauge the marginal growth effects of nation building. That is, what is the marginal impact of an extra dollar of economic aid when there is also military assistance and the presence of conflict. This requires testing the simple linear restriction $\left(\widehat{\theta_{3}}+\widehat{\theta_{4}}+\widehat{\theta_{9}}+\widehat{\theta_{10}}\right)=0$. Using parallel logic, assessing the marginal impact of postconflict nation building, we test the linear restriction $\left(\widehat{\theta_{3}}+\widehat{\theta_{5}}+\widehat{\theta_{9}}+\widehat{\theta_{11}}\right)=0$.

Results of interaction tests are reported at the bottom of Table 1. We can confidently reject the null on both counts. More specifically, using our instrumented measure of nation-building during conflict, a $1 \%$ increase in economic aid during times of conflict and military assistance translates into a roughly $1.4 \%$ increase in growth. On the other hand, using our estimated nationbuilding measure during post-conflict, a $1 \%$ increase in economic aid with military assistance after conflict translates into a roughly $4.5 \%$ decrease in growth. This suggests that nation building endeavors do help with economic growth, but that once the conflict is over persisting in nation building activity harms growth.

Determining whether economic and military aid tend to complement each other or crowd each other out, is tantamount to inquiring over the sign of $\left(\frac{\partial^{2} \Delta y}{\partial m i l i t a r y \partial l n(e c o n)}\right)$. During times of peace, there seems to be no relationship between combined economic and military aid and per capita growth. However, the conflict environment does seem to matter here. Simultaneous allocation of economic and military assistance during conflict has positive effects on growth (although this result is insignificant in the instrumented case). This may indicate some complementarities in assistance - economic aid works better in conflict environments when it is buttressed with military assistance that can provide security. On the other hand, joint assistance after conflicts harms economic growth. This may 
Table 1-Fixed Effects Estimation of Aid and Conflict Measures

Dependent VARiable is $\ln y_{j}(t+T)-\ln \left(y_{j}(t)\right)$

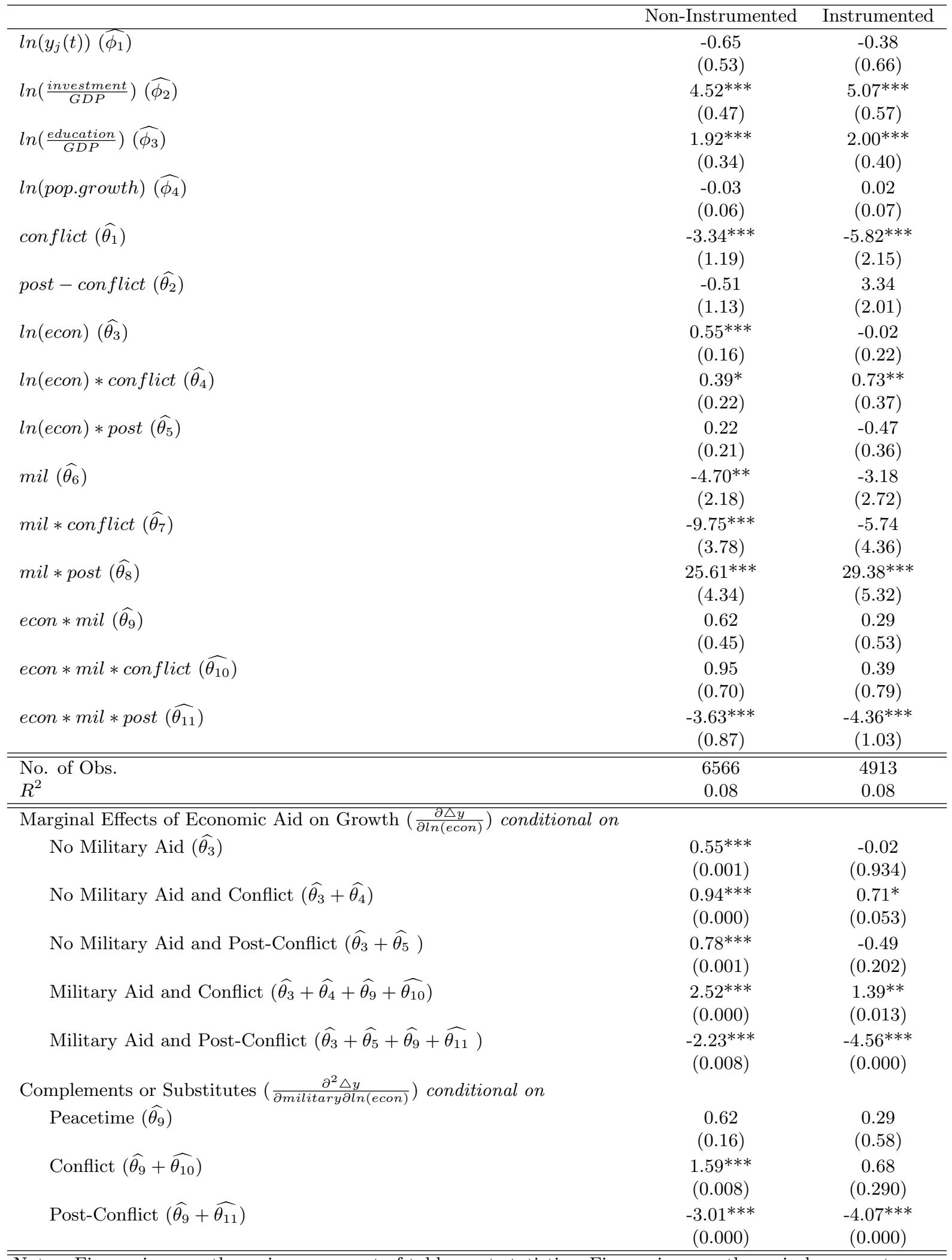

Notes: Figures in parentheses in upper part of table are t-statistics. Figures in parentheses in lower part of table are p-values. Significant at $1 \% * * *$, significant at $5 \% * *$, and significant at $10 \% *$. $\phi^{\prime} s$ and $\theta^{\prime} s$ refer back to the notation from equation (1). 
indicate a type of crowding out - economic support may thwart the natural forces of post-conflict development and reconstruction.

At this point one might ask what factors are driving the general results. That is, can we open up the black box of aid to get a better sense of which aid projects do the most good in terms of growth? To that end we splinter our aid measures into finer categories. More specifically, we first use the International Military Intervention Dataset (2008) to construct nine indicator variables for foreign military interventions instead of one. These nine (not mutually-exclusive) categories delineate the stated purpose of military involvement. For these regressions we keep our original general measure of economic aid. In a similar vein, we use data from the World Bank Projects Database (2008) to construct seven different measures of economic aid based on explicitly stated purposes.

Our results suggest that some kinds of assistance promote growth during turmoil and others are good for growth in the immediate aftermath of conflict. This should be of interest to potential nation builders they should be wary of lingering once conflict ceases, but if they must persist there are certain projects that would be more fruitful than others in promoting growth. In terms of types of military assistance during conflict, the maximum growth impacts are associated with traditional hardpower military operations, like missions to restore the balance of power. However, in the post conflict period, if a military presence remains, soft-power operations like diplomatic and humanitarian missions tend to have the highest degree of complementarity with the economic aid being given. The results also vary by type of economic aid. Infrastructure projects tend to stimulate growth both during and directly after conflict while spending on environmental projects have a significant effect only during conflict. Lastly, military interventions vary in their degree of intrusion starting with simply providing military transport, then patrol, intimidation, and finally combat. Interestingly, the only level of mil- itary intervention that produces a positive impact on economic growth both during the conflict and post conflict period is combat. This may indicate that a nation building operation should only be performed when the situation calls for military troops.

\section{Conclusions}

This analysis suggests that during conflict nation building endeavors by foreign countries can help a recipient nation increase its growth rate. In general there appears to exist certain complementarities between economic and military aid during times of war. Once conflict concludes we suggest that growth prospects are strongest with continued military presence but receding economic aid. An excessive foreign presence in the form of combined economic and military assistance can in fact hinder the natural re-building phase of a post-conflict region.

\section{REFERENCES}

Alesina, Alberto, and David Dollar. 2000. "Who Gives Aid To Whom And Why?" Journal of Economic Growth, 5(1): 33-63.

Collier, Paul, and Anke Hoeffler. 2002. "Aid, Policy, and Growth in Post Conflict Societies." The World Bank Working Paper 2927.

Durlauf, Steven, and Danny T. Quah. 1998. "The New Empirics of Economic Growth." National Bureau of Economic Research Working Paper.

Islam, Nazrul. 1995. "Growth Empirics: A Panel Data Approach." The Quarterly Journal of Economics, 110(4).

Solow, Robert M. 1956. "A Contribution to Theory of Economic Growth." The Quarterly Journal of Economics, 70.

Yamarik, Steven J., Noel D. Johnson, and Ryan A. Compton. 2010. "War! What Is It Good For? A Deep Determinants Analysis of the Cost of Interstate Conflict." Peace Economics, Peace Science and Public Policy, 16(1). 